\title{
Appraisal of national and international uterine fibroid management guidelines: a systematic review
}

\author{
Alison Amoah ${ }^{1}$, Nikhitha Joseph ${ }^{1}$, Sophie Reap ${ }^{1}$, and Stephen Quinn ${ }^{1}$ \\ ${ }^{1}$ Imperial College Healthcare NHS Trust
}

April 22, 2021

\begin{abstract}
Background Guidelines standardise high-quality evidence-based management strategies for clinicians. Uterine fibroids are a highly prevalent condition and may exert significant morbidity. Objectives The purpose of this study was to appraise national and international uterine fibroid guidelines using the validated AGREE-II instrument. Selection Strategy An electronic database search of PubMed and EMBASE from inception to October 2020 for all published English-language uterine fibroid clinical practice guidelines was undertaken. Data Collection and Analysis 939 abstracts were screened for eligibility by two reviewers independently. Three reviewers used the AGREE-II instrument to assess guideline quality in six domains (scope and purpose, stakeholder involvement, rigour of development, clarity of presentation, applicability, and editorial independence). Recommendations were mapped to allow a narrative synthesis regarding areas of consensus and disagreement. Main Results Eight national (AAGL, SOGC 2014, ACOG, ACR, SOGC 2019, CNGOF, ASRM, and SOGC 2015) and one international guideline (RANZOG) were appraised. The highest scoring guideline was RANZOG 2001(score 56.5\%). None of the guidelines met the a priori criteria for being high-quality overall (score $>=66 \%$ ). There were 166 recommendations across guidelines. There were several areas of disagreement and uncertainty. Conclusions There is a need for high-quality fibroid guidelines given heterogeneity across individuals and a large range of treatment modalities available. There are also areas of controversy in the management of fibroids (e.g. Ulipristal acetate, power morcellation) which also should be addressed in any guidelines. Future guidelines should be methodologically robust to allow high-quality decision-making regarding fibroid treatments.
\end{abstract}

\section{Hosted file}

Guidelines manuscript v1.2 SDQ.pdf available at https://authorea.com/users/409338/articles/ 519072-appraisal-of-national-and-international-uterine-fibroid-management-guidelines-asystematic-review

\section{Hosted file}

Figure 1 PRISMA flowchart of included studies.pdf available at https://authorea.com/ users/409338/articles/519072-appraisal-of-national-and-international-uterine-fibroidmanagement-guidelines-a-systematic-review

\section{Hosted file}

Figure 2 Overall scores for included guidelines.pdf available at https://authorea.com/ users/409338/articles/519072-appraisal-of-national-and-international-uterine-fibroidmanagement-guidelines-a-systematic-review

\section{Hosted file}

Figure 3 Scores for guideline domains.pdf available at https://authorea.com/users/409338/ articles/519072-appraisal-of-national-and-international-uterine-fibroid-management- 
guidelines-a-systematic-review

\section{Hosted file}

Table 1 Quality indicator for each of the 23 items of the AGREE-II instrument for each guideline.pdf available at https://authorea.com/users/409338/articles/519072-appraisal-of-national-andinternational-uterine-fibroid-management-guidelines-a-systematic-review 